\title{
Hyperbranched Polymers in a Supercritical Fluid: Recent Progress on Phase Behavior and Modeling
}

\author{
Yue $\mathrm{Wu}^{*}$ \\ Department of Chemical and Life Science Engineering, Virginia Commonwealth University, Richmond, \\ Virginia, 23284, USA
}

\begin{abstract}
The advent of new chemistries has led to the creation of well-defined, novel polymer architectures. Due to their unique structures, hyperbranched polymers are receiving more and more attention and widely applied in various fields in the past two decades. In spite of their increasingly mature applications, some fundamental properties of star polymers are still lacking, such as their solubility behavior in different solvents, especially at high pressures. On the other hand, supercritical fluids (SCF) are ideal environmentally preferable solvents for polymer processing. This article intends to review the recent progress on the experimental determination and modeling of phase behavior of hyperbranched polymer systems, especially hyperbranched polymers in SCF. Following a brief description of the definition, properties, and applications of hyperbranched polymers, a detailed overview will be presented on the recent studies on phase behavior of hyperbranched polymer systems. Emphasis will be laid on the high-pressure phase behavior of polymers in SCF. Different models proposed by previous researchers will be then compared for the purpose of accurately predicting the phase equilibrium data. Finally current challenges will be discussed for future work.
\end{abstract}

Keywords: Dendritic structure, phase equilibrium, high pressure, PC-SAFT, lattice cluster theory, Boltorn.

\section{INTRODUCTION}

Over the past decades, a great number of novel polymers with unique well-defined architectures have been created with the advent of new chemistries. Hyperbranched polymers, one of those uniquely structured macromolecules, have been attracting more and more attentions. They are essentially globular and they do not exhibit chain entanglements, leading to their low melt viscosity. They possess a large number of functional groups within a single molecule, and the functional groups can be readily modified to control their physical properties for specific uses. Their simple synthesis processes are another benefit for scale-up industrial applications. Those unique properties ensure their wide applications in various fields. Compared with their increasingly mature applications, the fundamental research on the physical chemistry properties is still in its infancy, such as solubility and phase transition data especially at various temperatures and pressures, let alone modeling. In the past eight years more and more researchers have noticed the gap and devote themselves to this area, generating a number of experimental data and predicting them with different models.

On the other hand, supercritical fluids (SCF) have been extensively studied for the past 40 years as environmentally friendly solvents for solution coatings, powder formation, and polymer purification and

\footnotetext{
*Address correspondence to this author at the Department of Chemical and Life Science Engineering, 601 West Main Street, Room 445, Richmond, VA 23284, USA; Tel: +1-8048227136; E-mail: wuy@vcu.edu
}

fractionation [1]. The combination of hyperbranched polymers and SCF has been receiving a number of attentions in the past five years accompanied with an increasingly deeper understanding of the solution properties of hyperbranched polymer systems. Generally, from the point of fundamental studies, there are two major advantages for the phase behavior investigation of a hyperbranched polymer in a SCF solvent. First, the phase behavior of a polymer in these common SCF has been extensively studied from both experimental determination and modeling work [2]. The comparison of hyperbranched polymer - SCF mixture with its comparable linear polymer in these commonly used SCF can give an insight about the architectural effects of hyperbranched polymers on the phase behavior and the performance of different models. Secondly, since most commonly used supercritical fluids, such as carbon dioxide and propane, are very small molecules with not very strong solvent power, a slight structural difference can spread out and be clearly reflected on the phase diagram of a polymer in one of those small molecules.

Therefore, this article intends to review the recent progresses of the experimental determination and modeling on the phase behavior of hyperbranched polymer systems at different temperature and pressure conditions. Starting with a brief description of hyperbranched polymer definitions, unique properties and applications, phase behavior results from recent studies will be detailed. Special attention will be given to the high-pressure phase behavior investigation of a hyperbranched polymer in a supercritical fluid, followed 
by several models proposed to predict those phase transition data. Last, several challenges in this area will be put forward by the author for future work.

\section{DEFINITIONS, PROPERTIES, AND APPLICATIONS}

Hyperbranched polymers are highly branched macromolecules with three-dimensional dendritic architecture [3], although up to now still not a very refined definition is assigned to the term "hyperbranched polymers" partly because of the word "hyperbranched". In addition to random hyperbranched polymers, some polymers also exhibit highly branched structures or dendritic architectures, while they are usually given as different names, for example, "dendrimers", "dendrigrafts", and "star polymers". Figure 1 shows the structures of different types of polymers with dendritic architectures from Gao, et al. [3]. Note that the term "hyperbranched polymer" in Figure 1 means random hyperbranched polymer.

Generally speaking, those polymers with dendritic architectures like dendrimers, dendrigrafts, and star polymers are different types of hyperbranched polymers and they are included in the term "hyperbranched polymers" in some academic researches and commercial uses. On the other hand, other studies only consider the random hyperbranched polymers as "hyperbranched polymers" and other dendritic structured polymers have their own names although they exhibit highly branched architecture, given that random hyperbranched polymers have their own unique properties and advantages. For example, compared with dendrimers which exhibit perfection in structures and require complicated multistep synthesis, random hyperbranched polymers have larger polydispersity and irregularity in the structure and can be easily synthesized via one-step or two-step reactions, which is especially beneficial for those applications that do not require structural perfection. Further, those different types of highly branched macromolecules are not entirely independent. For example, some star polymers can be synthesized by a hyperbranched polymer as the core and other polymers such as copolymer as the arms [4]. In this paper, the term "hyperbranched polymers" means random hyperbranched polymers unless noted clearly elsewhere.

The most common method for preparing hyperbranched polymers is the polycondensation of $A B_{m}$ monomers, which is performed in concurrent mode or by slow addition of the branching $A B_{m}$ monomer. However this approach is not desired when requiring a narrow molecular weight distribution for hyperbranched polymers [5]. Hence, a large number of researches focus on narrowing the molecular weight distribution via different synthesis methods, which can be found from several reviews [3, 6-11].

As is briefly mentioned above, the hyperbranched polymers have a number of unique properties. They are essentially globular and do not exhibit chain entanglements, leading to the low viscosity of polymer melts and polymer solutions. For example, Ye, et al.

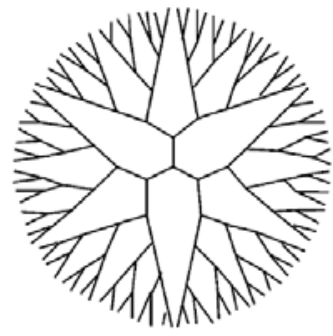

Dendrimer

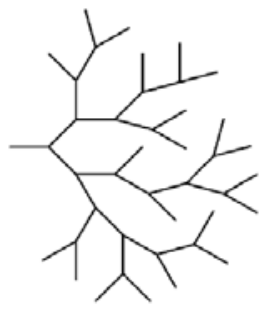

Hyperbranched polymer

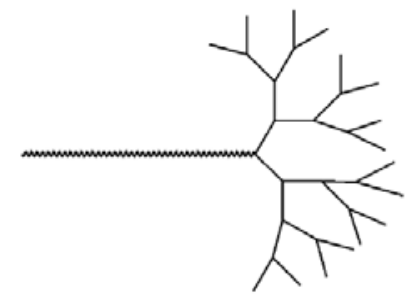

Linear-dendritic hybrid

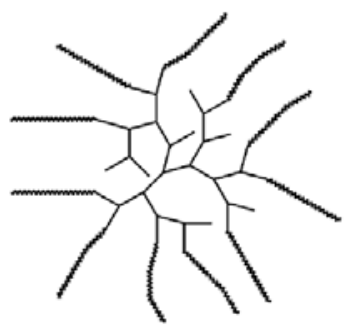

Multi-arm star polymer

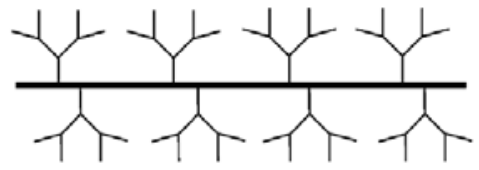

Dendronized polymer or Dendrigrafted polymer

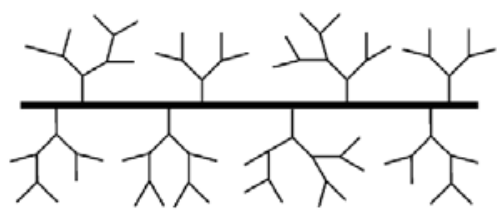

Hypergrafted polymer

Figure 1: Structures of polymers with dendritic architectures [3] 
$[12,13]$ investigated the melt rheological properties of hyperbranched polyethylenes, which is synthesized with the chain walking strategy [14]. They found that the hyperbranched polymer flow behavior, flow activation energy, and dynamic moduli are very different from linear polyethylene. The hyperbranched polymer exhibits very low melt viscosity and follows Newtonian flow behavior. Hyperbranched polymers also possess a large number of functional groups within a single molecule, and the functional groups can be readily modified to control their physical properties such as solubility in different solvents, compatibility with other large molecules, self-assembly, fluorescence, and electrochemical properties for specific uses. They can be synthesized via one-step or two-step reactions, making them promising for large-scale industrial applications. Further hyperbranched polymer properties can be found from Seiler's review [7, 9].

Those unique properties and easy synthesis process ensure their wide applications. For example, in the field of chemical engineering, hyperbranched polymers are promising entrainers for extractive distillation, extraction solvents for liquid-liquid extraction, and agents for gas absorption due to their high selectivity and separation efficiency, low melt and solution viscosities, noncorrosive and nontoxic behavior, relatively good thermal stabilities, and adjustable physical and chemical properties [7]. Seiler, et al. [15-18] evaluated the potential of using hyperbranched polyglycerol in the separation of the azeotropic system and they found that adding the hyperbranched polymer effectively broke the azeotrope. Rolker, et al. [19] investigated the absorption capabilities of several hyperbranched polymers for $\mathrm{CO}_{2}$ and nitrogen, showing that the hyperbranched polymers are promising as gas absorbers with high selectivity. In the field of lubricant industry, hyperbranched polymers can be used as rheology modifiers. Wang, et al. [20] investigated the potential of hyperbranched high-molecular-weight polyethylenes as lubricant viscosity-index improvers. They found that the hyperbranched polyethylene exhibited high shear stability with almost zero shear degradation, although its viscosity thickening power is lower than the linear polymer. In the field of biomedical engineering, hyperbranched polymers are widely used as micro- or nano-capsules as a carrier for drug delivery system [21-24]. Suttiruengwong, et al. [24] compared the feasibility of hyperbranched polymers as drug carriers with different microencapsulation methods and the release behavior with different loading methods using a commercially available hyperbranched polyester as a carrier and acetaminophen as a model drug. They concluded that release kinetics depends on the method used to prepare microcapsules. More applications of hyperbranched polymers can be found in $[3,7-9,11,25,26]$.

\section{PHASE BEHAVIOR OF HYPERBRANCHED POLYMER SYSTEMS}

Despite wide applications in a large number of fields, some fundamental data such as phase behavior and $p V T$ results of hyperbranched polymer solutions are still scarce, especially at high pressures. Such data may play a key role in the successful applications to a field. For example, in the field of oil industry, the hyperbranched polymers can be used as additives in engine oils for lubrication. The combustion in the engine will generate a very high pressure and temperature conditions, leading to the possible phase separation of hyperbranched polymers and oils, which may cause clogging problems. To this perspective, phase behavior data of hyperbranched polymers in oils are very important over a wide range of pressures and temperatures. Further, the phase behavior data along with high-pressure density data are needed for the optimization of parameters in some models.

Seiler [7] gave a general overview of phase behavior of branched polymers, hyperbranched polymers, and dendrimers in different solvents. However, the majority of the phase behavior data are obtained at low pressures before the year 2005. In the past eight years, an increasing number of researchers have noticed the gap. More and more original highpressure liquid-liquid phase equilibrium data are reported by several groups in addition to the lowpressure vapor-liquid equilibrium results. On the other hand, supercritical fluids (SCF) have been known for over 100 years and studied extensively for decades of years. A larger number of papers have been published on the use of SCF as ideal environmentally preferable solvents for polymer processing [1, 27-30]. All those SCF-based processing technology requires a solid understanding of the polymer-SCF solution behavior. Kirby and McHugh made a detailed review on the phase behavior and modeling of homopolymer, copolymer, and fluoropolymer in SCF [2]. The section of this article will focus on the recent progresses on experimental phase behavior results of hyperbranched polymer systems, especially high-pressure results in a supercritical fluid. Some hyperbranched polymers commonly used in recent phase behavior studies will 


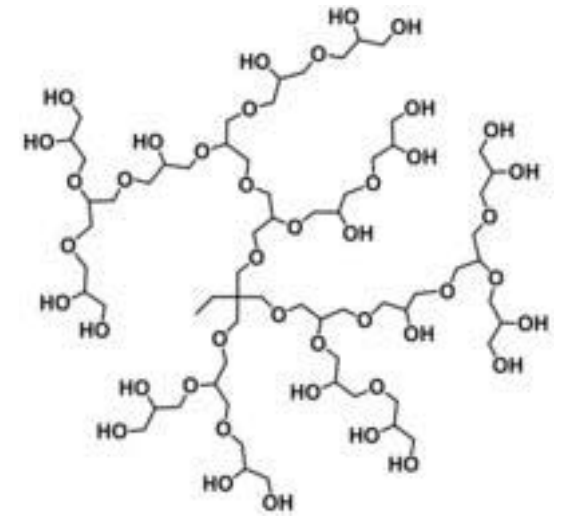

(a)

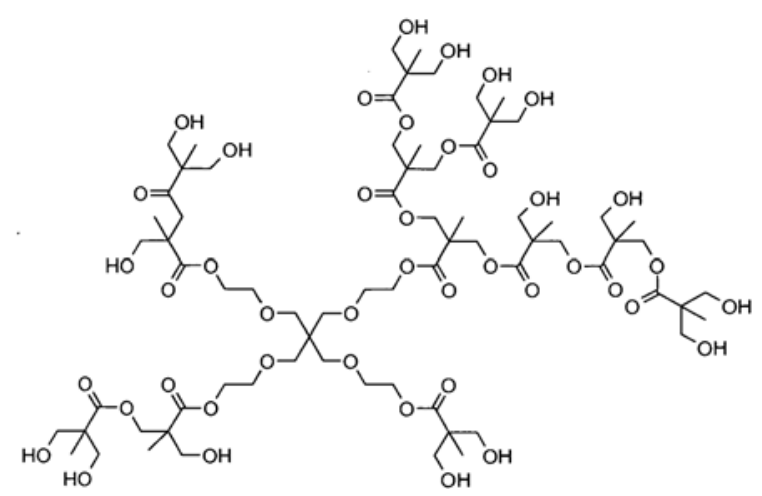

(b)

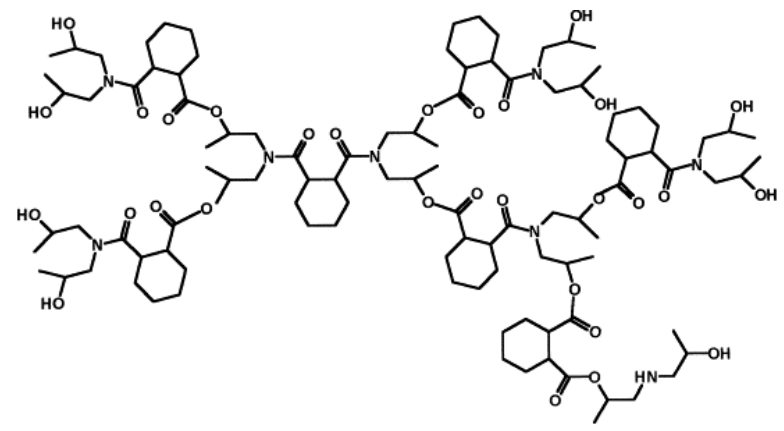

(c)

Figure 2: Structures of commercial hyperbranched polymers, (a) hyperbranched polyglycerol, (b) hyperbranched polyester (Boltorn ${ }^{\circledR}$ series), and (c) hyperbranched polyesteramide (Hybrane ${ }^{\circledR}$ series).

be introduced first, followed by an overview of recent progresses on low-pressure phase behavior. Then in the high-pressure phase behavior section, after a brief description of experimental methods used for highpressure determination, a detailed review on the highpressure phase behavior studies will be presented.

\subsection{Materials}

Up to now, several commercially available hyperbranched polymers are used in most recent phase behavior studies. Figure 2 shows the structures of these common commercial polymers including hyperbranched polyglycerol, hyperbranched polyester
(Boltorn ${ }^{\circledR}$ series), and hyperbranched polyesteramide (Hybrane ${ }^{\circledR}$ series). Among those polymers, the Boltorn ${ }^{\circledR}$ series polyesters with different terminal groups are the most studied in recent phase behavior researches. Table 1 shows the nominal molecular weight $\left(M_{w}\right)$ and structural information about various derivatives of Boltorn ${ }^{\circledR}$ series polymers obtained from the polymer supplier website [31].

In addition to the commercially available hyperbranched polymers, some researchers [32, 33] have been focusing on synthesis of their own hyperbranched polymers with desired structures to

Table 1: Nominal Molecular Weight $\left(M_{w}\right)$ and Structural Information of Boltorn ${ }^{\circledR}$ Series Hyperbranched Polyesters [31]

\begin{tabular}{|c|c|c|}
\hline Commercial Name & Nominal $\boldsymbol{M}_{\boldsymbol{w}}$ & Structural Information \\
\hline \hline Boltorn $^{\circledR} \mathrm{H} 20$ & 1,750 & 16 terminal hydroxyl groups \\
\hline Boltorn $^{\circledast} \mathrm{H} 30$ & 3,608 & 32 terminal hydroxyl groups \\
\hline Boltorn $^{\circledR} \mathrm{H} 40$ & 7,323 & 64 terminal hydroxyl groups \\
\hline Boltorn $^{\circledR} \mathrm{H} 2004$ & 3,100 & 6 terminal hydroxyl groups \\
\hline Boltorn $^{\circledast} \mathrm{H} 3200$ & 10,500 & Hydroxyl terminal groups functionalized with a mixture of eicosanoic and docosanoic acid \\
\hline Boltorn $^{\circledast} \mathrm{U} 3000$ & 6,500 & Modified with unsaturated fatty acid \\
\hline Boltorn $^{\circledast}$ W3000 & 10,000 & Modified with non-ionic groups and unsaturated fatty acid \\
\hline
\end{tabular}


isolate and study the effect of a single factor on the phase behavior of hyperbranched polymer systems. The information of those customized polymers will be detailed in Section 3.3.2.

\subsection{Low-Pressure Phase Behavior}

Domanska, et al. [34-40] reported a number of experimental phase behavior data of the binary and ternary mixture of the commercial hyperbranched polyesters, Boltorn ${ }^{\circledR} \mathrm{U}-3000, \mathrm{~W}-3000$, and $\mathrm{H}-2004$, in various solvents such as alcohols, hydrocarbons, and ethers, with different compositions over a wide temperature range at ambient pressure. Liquid-liquid phase equilibrium results were obtained for Boltorn ${ }^{\circledR}$ U3000, W3000, and H2004 [35, 36, 38-40] and the solid-liquid phase equilibrium data were determined for Boltorn ${ }^{\circledR}$ W3000 [39]. The temperature - composition $(T-x)$ diagrams were reported along with the actual data points with different compositions and temperatures at ambient pressure. Domanska, et al. [34, 37] also determined the densities and viscosities of the binary mixtures of Boltorn ${ }^{\circledR}$ polymers (Boltorn ${ }^{\circledR}$ U3000 and Boltorn $\left.{ }^{\circledR} \mathrm{H} 2004\right)$ in alcohols or ethers with different compositions at temperatures up to $338.15 \mathrm{~K}$. Negative deviations were found for excess volumes and viscosities in both cases, indicating the dispersion interaction dominates the interactions between the hyperbranched polymer and the solvent. The effect of the alcohol chain length was also investigated on the mixture densities and viscosities. With the increase in the alkyl group number in an alcohol, a modest increase was observed for the mixture density while a more noticeable increase for the viscosity.

Enders' group [41-44] reported the liquid-liquid phase equilibrium (LLE) data of the binary and ternary system containing Boltorn ${ }^{\circledR}$ series hyperbranched polyester in water and/or alcohol with different compositions and temperatures at ambient pressure for their further lattice cluster theory (LCT) modeling studies. The liquid-liquid phase behavior results they reported are found to be very different from those found by Jang and Bae before [45]. The authors gave a possible explanation that the phase transition data determined by Jang and Bae might be SLE data instead of LLE data given the fact of the melting temperature of Boltorn ${ }^{\circledR} \mathrm{H} 20$ above $323 \mathrm{~K}$ [42]. In the case of the binary mixture of Boltorn ${ }^{\circledR} \mathrm{H} 40$ and water, the LLE data was determined very carefully to avoid the decomposition of the polymer due to the limited thermal stability of the aqueous Boltorn ${ }^{\circledR} \mathrm{H} 40$ solutions after a longer time staying at temperatures near the phase transition point, which was found with size exclusion chromatography by the authors [43]. It should be noted that each LLE temperature of Boltorn ${ }^{\circledR} \mathrm{H} 20$ solution at a given composition was taken as the average of the phase change temperature by heating up and the temperature by cooling down, while the LLE temperature of Boltorn ${ }^{\circledR} \mathrm{H} 40$ solution was only taken as the temperature by cooling down.

Seiler, et al. [15-18, 46, 47] focused on the phase behavior of commercial hyperbranched polymers such as hyperbranched polyglycerol, Boltorn ${ }^{\circledR}$ series hyperbranched polyester, and Hybrane series ${ }^{\circledR}$ hyperbranched polyesteramide in azeotropic systems such as ethanol + water and tetrahydrofuran + water to assess the potential application of hyperbranched polymers as additives for the separation of azeotropic mixtures with extractive distillation. The gravimetric method and headspace-gas chromatography (HSFC) [48] were used to determine the phase behavior of binary and ternary mixture, respectively. The effects of branching, molecular weight, and number of functionalities were discussed. The influence of hydrogen bonding was also considered. It was found that the addition of hyperbranched polyglycerol and polyesteramide can break the azeotropic behavior of various systems including ethanol + water, 2-propanol + water, and tetrahydrofuran + water due to the formation of hydrogen bonds between polymer and water molecules. The solubility behavior of such polymers increased with the decrease in molecular weight and the separation factor of the azeotropic system increased in the number of functional groups such as surface hydroxyl groups in the hyperbranched polyglycerol molecule [15]. However, the hyperbranched polyester molecules tended to form agglomerates, affecting their solubility and separation efficiency.

Rolker, et al. [19] investigated the solubility behavior of $\mathrm{CO}_{2}$ and nitrogen in different polymers including linear and branched polyethers, hyperbranched polyesters and polyamines in terms of Henry constants. The selectivity of the polymers for the gases and the enthalpies of absorption at infinite dilution were determined. The results showed that the aqueous polyamidoamine dendrimer solution had a good solubility of $\mathrm{CO}_{2}$ and selectivity toward nitrogen.

\subsection{High-Pressure Phase Behavior}

\subsubsection{Experimental Methods}

A large number of methods were developed today for the determination of high-pressure phase equilibria. 
The details can be found in several reviews [49-53]. This article will focus on two experimental apparatus used in recent studies on hyperbranched polymer phase behavior determination, Cailletet apparatus and variable-volume high-pressure view cell, both of which belong to the category of "synthetic method with a phase transition" defined by Dohrn, et al. [53]. Based on over 140-year-old design, Cailletet apparatus mainly consists of a thick-walled glass tube. Samples are filled into the tube and the open end of the tube is then immersed in the mercury, which separates the samples from the pressurizing fluid. The phase transition is determined visually by changing the pressure slowly at a constant temperature. The detailed description and schematic diagram of the Cailletet apparatus can be found in $[54,55]$. One of the disadvantages, however, for this system is the needs for handling hazardous mercury. Further, the glass tube limits the use of the apparatus at ultra-high pressures.

A more popular apparatus for high-pressure phase behavior studies nowadays is the variable-volume highpressure view cell, which can avoid the use of mercury and reach ultra-high pressures. Figure $3 \mathbf{a}$ shows a schematic diagram of a typical variable-volume highpressure view cell. The cylindrical cell body is constructed of metal such as high nickel content steel to ensure the strength. Along its cylindrical axis a bore is drilled for placing samples. A sapphire window is sealed at one end of the bore for the visual observation inside with the help of a borescope. The other end is placed by a movable piston. The cell contents are compressed to the desired operating pressure by displacing a piston in the cell. Close to the sapphire window, there are several side ports for mounting temperature and pressure detectors as well as side sapphire windows for the laser and sensor to automatic record the phase transition point based on the intensity change.

Another advantage of the equipment is its capability of combining high-pressure density measurements. As is shown in Figure $\mathbf{3 b}$, a rod with a magnetic core end is connected to the piston and travels through a linear variable differential transformer (LVDT), which records the piston position and can be translated to the internal volume of the cell. Knowing the amount of the samples loaded into the cell, the densities at each pressure level can be calculated.

\subsubsection{Progress on High-pressure Phase Behavior}

Besides the low-pressure studies mentioned above, Seiler, et al. [57] are the pioneers who reported the phase behavior data of binary and ternary mixtures containing Boltorn ${ }^{\circledR}$ series hyperbranched polyesters at elevated pressures with a variable-volume autoclave $[58,59]$. While the phase transition pressure of the binary mixture of polymer-water is lower than $0.6 \mathrm{MPa}$ at the temperature up to $433 \mathrm{~K}$, the upper critical solution temperatures (UCST) and lower critical solution temperatures (LCST) were determined for the hyperbranched polyester solutions in either water or ethanol at the presence of supercritical $\mathrm{CO}_{2}$ at the pressures up to $18 \mathrm{MPa}$. The $\mathrm{pH}$ effect on UCST was also discussed by comparing the effects of $\mathrm{CO}_{2}$ concentrations in two ternary systems, polymer + water $+\mathrm{CO}_{2}$ and polymer + ethanol $+\mathrm{CO}_{2}$, based on the fact that the easy dissolution of $\mathrm{CO}_{2}$ in water led to the decrease in $\mathrm{pH}$ for the polymer-water- $\mathrm{CO}_{2}$ system while the difficulty in dissolving $\mathrm{CO}_{2}$ in ethanol made the $\mathrm{pH}$ condition unchanged for polymer + ethanol + $\mathrm{CO}_{2}$ system as the $\mathrm{CO}_{2}$ concentration increased. It was found that the decrease in $\mathrm{pH}$ lowered the UCST, indicating an increase in polymer solubility at lower $\mathrm{pH}$. Seiler [7] also reported density data for hyperbranched polyglycerol and Boltorn ${ }^{\circledR} \mathrm{H} 20$ at the temperatures up to $423.15 \mathrm{~K}$ and pressures up to $60 \mathrm{MPa}$.

Following Seiler's work, more and more researchers have been making a sustained effort to generate highpressure phase equilibrium data in the past five years. Researchers at Delft University of Technology [60-62] reported the high-pressure phase behavior results of

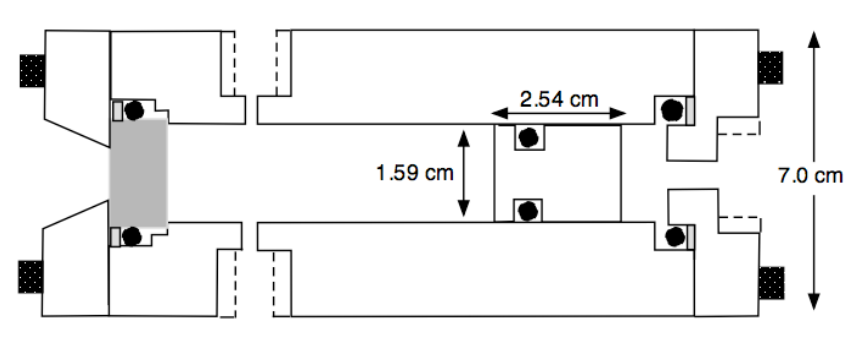

(a)

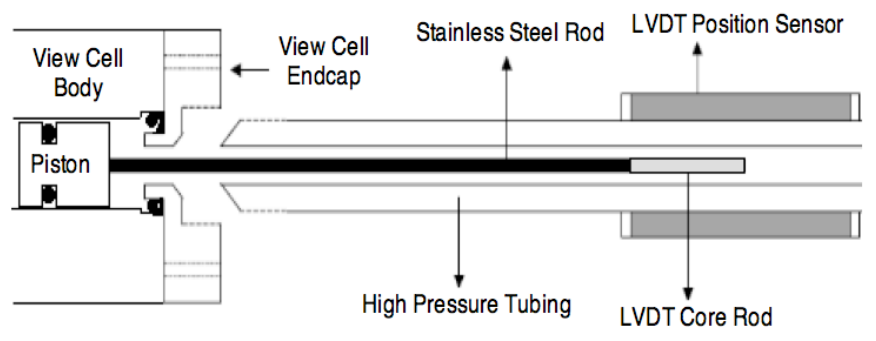

(b)

Figure 3: Schematic diagram of (a) variable-volume high-pressure view cell, (b) combination of a linear variable differential transformer (LVDT) for high-pressure density measurement [56]. 
binary system of hyperbranched polyester in supercritical $\mathrm{CO}_{2}$ and propane as well as the ternary mixture of hyperbranched polyglycerol + methanol + $\mathrm{CO}_{2}$ with the Cailletet apparatus. A variety of phase equilibrium data were determined at pressures up to 15 $\mathrm{MPa}$, including vapor-liquid equilibrium for Boltorn ${ }^{\circledR}$ $\mathrm{U} 3000+\mathrm{CO}_{2}$; vapor-liquid, liquid-liquid, liquid-liquidvapor, solid-liquid-liquid, and solid-liquid-vapor equilibrium for Boltorn ${ }^{\circledR} \mathrm{H} 3200$ + propane; and vaporliquid, liquid-liquid, and liquid-liquid-vapor equilibrium for hyperbranched polyglycerol + methanol $+\mathrm{CO}_{2}$. The phase behavior of hyperbranched polyglycerol + methanol $+\mathrm{CO}_{2}$ was also compared with the ternary system of linear polyglycerol in the same solvents [62, 63]. The bubble-point pressures for the linear polymer system did not change much with the increase in the molecular weight of the polymer, while for hyperbranched polymer system the molecular weight showed a more pronounced effect on the bubble-point pressures, indicating that the branched structure is the main reason for the dependence of bubble-point pressures on the polymer size. It was also found that the polymer concentration at UCST for the hyperbranched polymer was much higher than its corresponding linear polymer.

Unlike the commercial hyperbranched polymers with fixed structures used in the above studies, Gregorowicz, et al. [32] made an original contribution to customize the hyperbranched polyether and polyester by modifying the terminal $-\mathrm{OH}$ groups with aliphatic carboxylic acids derivatives, trimethylchlorosilane, and trifluoroacetic acid anhydride for the purpose of tailoring the solubility of polymers in supercritical $\mathrm{CO}_{2}$. Figure 4 shows the structure of each type of terminal groups used for the substitution of the original $-\mathrm{OH}$ group in the hyperbranched polyether and polyester. The phase behavior of the hyperbranched polymers with a variety of terminal groups was determined in supercritical $\mathrm{CO}_{2}$, ethane, and propane at pressures up to $200 \mathrm{MPa}$. The effects of types and length of terminal groups and interior architecture of hyperbranched polymers were investigated. A number of interesting observations were found. For example, the original hyperbranched polyether and polyester cannot be dissolved in supercritical $\mathrm{CO}_{2}$ at pressures up to 200 $\mathrm{MPa}$ and temperatures up to $420 \mathrm{~K}$, while they become soluble by replacing the $-\mathrm{OH}$ terminal group with the above terminal groups due to the interaction of the solvent with the end groups in the polymer molecules, indicating that terminal groups play a significant role in the solubility of hyperbranched polymers. The phase transition pressure dependence on temperatures was also investigated by comparing different types of terminal groups.

Gregorowicz, et al. [32] also found that for the same type of terminal group such as aliphatic carboxylic acids, the phase transition pressure of hyperbranched polymers in $\mathrm{CO}_{2}$ was strongly dependent on the chain length of the alkyl group and polymer concentration. The phase transition pressure increased with the increase in chain length. The possible reason is that the long-chain end group may form a shell, preventing

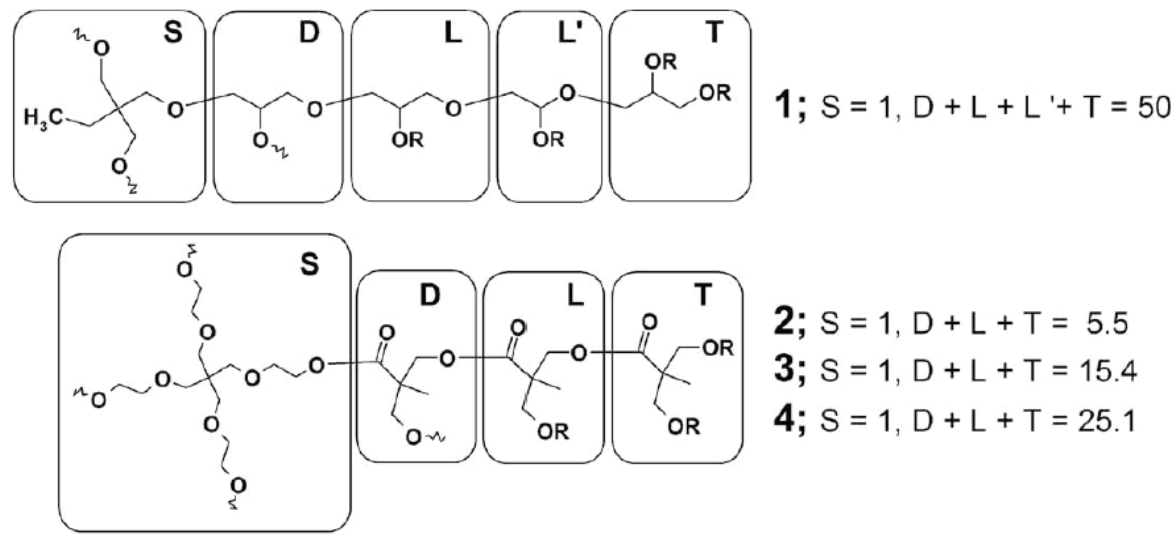

$$
\begin{aligned}
& \text { a; R }=-(\mathrm{CO}) \mathrm{CH}_{3} \\
& \text { b; } \mathrm{R}=-(\mathrm{CO})\left(\mathrm{CH}_{2}\right)_{5} \mathrm{CH}_{3} \\
& \mathbf{c} ; \mathrm{R}=-(\mathrm{CO})\left(\mathrm{CH}_{2}\right)_{10} \mathrm{CH}_{3} \\
& \text { d; } \mathrm{R}=-(\mathrm{CO})\left(\mathrm{CH}_{2}\right)_{16} \mathrm{CH}_{3} \\
& \text { e; R }=-(\mathrm{CO}) \mathrm{CF}_{3}
\end{aligned}
$$$$
\text { f; } \mathrm{R}=-\mathrm{CH}_{2}(\mathrm{CO}) \mathrm{OCH}_{2} \mathrm{CH}_{3}
$$$$
\text { g; } \mathrm{R}=-\mathrm{Si}\left(\mathrm{CH}_{3}\right)_{3}
$$$$
\mathbf{h} ; \mathrm{R}=-\left[(\mathrm{CO})\left(\mathrm{CH}_{2}\right)_{5} \mathrm{O}\right]_{5} \mathrm{Si}\left(\mathrm{CH}_{3}\right)_{3}
$$$$
\mathrm{i} ; \mathrm{R}=-\left[(\mathrm{CO}) \mathrm{O}\left(\mathrm{CH}_{2}\right)_{3} \mathrm{O}\right]_{5}(\mathrm{CO}) \mathrm{CH}_{3}
$$$$
\mathbf{j} ; \mathrm{R}=-\left[(\mathrm{CO})\left(\mathrm{CH}_{2}\right)_{5} \mathrm{O}\right]_{5}(\mathrm{CO}) \mathrm{CH}_{3}
$$

Figure 4: Structures of the derivatives of hyperbranched polyether and polyester with different types of terminal groups [32]. 
the solvent molecules from going into the interior of the polymer while the short-chain alkyl group does not. And the increase in the composition of the polymer led to the decrease in phase transition pressure. The effect of interior architecture was also investigated based on the comparison of phase behavior data between hyperbranched polyether and hyperbranched polyester with the same terminal group. However, the interior architectural effect was not very well isolated from the molecular weight effect. Further, the authors compared the solubility behavior of their modified hyperbranched polymers with some commonly used $\mathrm{CO}_{2}$-philic polymeric materials in supercritical $\mathrm{CO}_{2}$ and light hydrocarbons and showed that the hyperbranched polyester with silane and fluorinated end groups was soluble in $\mathrm{CO}_{2}$ to the same extent with most $\mathrm{CO}_{2}$-philic polymers. Despite of many impressive results, still several mysteries remained, such as the unexpected phase behavior of certain hyperbranched polymers modified with caprolactone, silane, or fluorinated terminal groups.

Following Gregorowicz's work, Tryznowski, et al. [33] in the same research group synthesized hyperbranched polycarbonates with different types of terminal groups and compared the phase behaviors of the hyperbranched polymers in supercritical $\mathrm{CO}_{2}$ with those of linear polycarbonates and hyperbranched polyesters. The hyperbranched polycarbonate with fluorinated terminal groups was found to be dissolved in supercritical $\mathrm{CO}_{2}$ while the same type of hyperbranched polymer with hydroxyl terminal groups was not soluble at the temperatures up to $423 \mathrm{~K}$ and pressures up to $150 \mathrm{MPa}$, verifying the terminal group effect. Different concentrations of hyperbranched polycarbonate with fluorinated terminal groups showed different types of phase behavior. When increasing temperature, the phase transition pressure increased for the low concentration of the polymer, whereas the pressure decreased for the polymer concentration higher than $3.5 \mathrm{wt} \%$. Further, the phase transition pressure of hyperbranched polyester with fluorinated terminal groups was lower than the hyperbranched polycarbonate with the same terminal groups at a similar polymer concentration and the same temperature range. The authors ascribed such a difference to the internal structure between polyether and polycarbonate. Since the polyester structure is more $\mathrm{CO}_{2}$-philic, the phase transition pressure of hyperbranched polyester should be lower. However, it should be noted that when making this point the authors did not mention the molecular weight difference of the two hyperbranched polymers, which was also a possible factor for the phase transition pressure difference. The effect of the chain lengths was also discussed by comparing the phase behavior of different types of linear polycarbonates.

\section{THERMODYNAMIC MODELING}

Experimental results on the phase behavior and density data offer a database for the theoretical researchers to develop and test suitable thermodynamic models to predict the solution behavior of hyperbranched polymer systems. Earlier modeling work includes Monte Carlo simulation by Lue [64] and Timoshenko and Kuznetsov [65], molecular dynamics method by Steinhauser [66], lattice cluster theory (LCT) modeling by Jang, et al. [45, 67-71], universal functional activity coefficients-free-volume (UNIFACFV) method by Kouskoumvekaki, et al. [72] and Seiler, et al. [47], etc., which have been reviewed by Seiler [7]. In the past eight years after the review, more models have been developed for hyperbranched polymer systems accompanied with a deeper understanding of the hyperbranched polymer architecture and an increasing number of low-pressure and high-pressure experimental data.

Rissanou, et al. [73] performed Monte Carlo simulations to investigate the phase behavior of lattice model dendrimers of generations from 2 to 5 in solution. The effect of branching on the polymer critical properties was calculated. It was observed that for higher generation dendrimers the infinite-system critical temperature decreased while the critical volume fraction increased. The radius of gyration was also calculated, showing the globular confirmation of the hyperbranched polymer.

Enders' group [41-44, 74, 75] predicted the lowpressure phase behavior of hyperbranched polyester systems with an incompressible LCT model. Compared with earlier work done by Jang, et al. [45, 67-71], the authors introduced several corrections and combined a more realistic method for determination of the geometric parameters [74]. In this model, only one parameter, the interaction energy, needed to be adjusted to the maximum of the cloud-point curve and the polymer architecture effect can be considered geometrically without any adjustable parameter [74]. To eliminate the drawback of lack of association force involved, the model was then improved by incorporation of the Wertheim lattice theory [42], which was originated from Wertheim for the purpose of 
describing the association with a perturbation theory [76-79]. The LCT model combined with Wertheim lattice theory exhibited an improvement of the phase behavior of binary system especially at higher polymer concentration [42], followed by the extension to ternary systems, hyperbranched polyester + propanol + water and hyperbranched polyester + 1-butanol + water, which LCT- Wertheim lattice theory model also showed a reasonable predictive capability $[41,44]$. A generalized LCT equation combined with a modified extended chemical association lattice model (ECALM) were also developed to allow both of the component molecules in a binary system to posses any architecture and describe both the self-association and cross-association for both components [75]. The generalized LCT-ECALM equation agreed well with various experimental data $[43,75]$.

Simha and Utracki [80] applied Simha-Somcynsky (S-S) equation of state (EOS) to predict the highpressure density data and the derivatives such as isothermal compressibility and thermal expansion coefficient for the linear polystyrene (PS) and poly(benzyl ether) dendrimers (PBED). By fitting the high-pressure density data from Hay, et al. [81] to the equation, the S-S EOS predicted the density data very well and also showed a good agreement for thermal expansion coefficient at ambient pressure, while the calculated isothermal compressibility was lower at low pressures and higher at high pressures than the experimental data. The calculated values of the second and higher derivatives with this equation were very different from the theoretical predictions and behavior of linear polymers, indicating that the model was not able to predict the pressure effects on the dendritic structure with variable segment density [80].

Kozlowska, et al. [60] proposed the perturbed-chain polar statistical association fluid theory equation of state for branched molecules (bPCP-SAFT) for highpressure phase behavior and densities predictions. Based on the classical perturbed-chain association fluid theory (PC-SAFT) proposed by Gross and Sadowski [82, 83], Gross, et al. [84-86] improved the original PC-SAFT model to the perturbed-chain polar statistical association fluid theory equation of state (PCP-SAFT) by taking into account the dipolar and quadrupolar interactions, followed by the bPCP-SAFT model by adding a branching term, which has been applied to complex molecules by Blas and Vega [87], to the original PCP-SAFT EOS. Like other SAFT-based models, bPCP-SAFT EOS represents the $p V T x$ relationship with Helmholtz free energy, which can be divided into several contributions. Keeping the hardchain contribution, dispersion contribution, and association contribution the same with PCP-SAFT, bPCP-SAFT equation adopts Wertheim's second-order perturbation theory (TPT2) for chainlike molecules and adds the Helmholtz free energy contribution from the branched structure, which does not introduce any more parameters other than the original three PC-SAFT parameters, the segment number, $m$, the temperatureindependent segment size, $\sigma$, and the energy interaction parameter, $\varepsilon / k_{B}$, for non-association systems, and two more parameters, association volume, $\kappa^{A i B j}$, and association energy, $\varepsilon^{A i B j} / k_{B}$ for association systems. Note that the branching term proposed here is only considered in the repulsive interactions, which was characterized as a "significant simplification" by the authors [60]. Further, the bPCPSAFT model assumes the branched structure is composed of branching tetramers shown in Figure $\mathbf{5}$ and the bond angle is $120^{\circ}$.

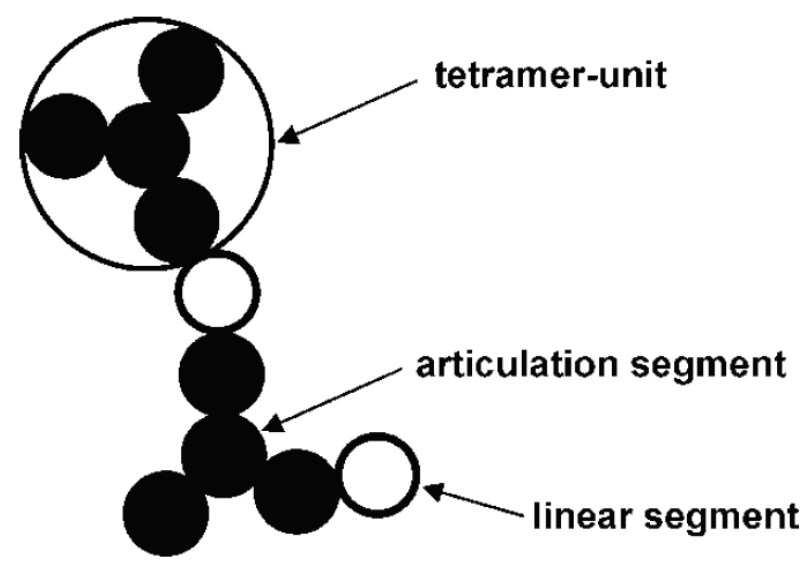

Figure 5: Schematic diagram of the branching tetramers that consist of the branched structure of a hyperbranched polymer [60].

The phase behavior of the ternary system of hyperbranched polyglycerol + methanol $+\mathrm{CO}_{2}$ was predicted with the bPCP-SAFT model and compared with the experimental data by Kozlowska, et al. [60]. The model gave a good prediction for the vapor-liquid phase equilibrium, although it only showed a modest improvement relative to the PCP-SAFT EOS. On the other hand, the bPCP-SAFT model was not able to predict the liquid-liquid and liquid-liquid-vapor phase equilibria at the right temperatures. The authors ascribed it to the overestimation of the hydrogen bonding interactions to methanol, since the association parameters of hyperbranched polyglycerol were estimated through analogy to 1-butanol, while the hyperbranched polymer has average less accessibility 
to the hydroxyl groups due to its structure and hence made a less contribution to the intermolecular interactions than 1-butanol. The overestimation led to the cross-association between the hyperbranched polymer and methanol that prevented the demixing of the two components [60].

For the purpose of solving the above problem of hydrogen bonding overestimation, following Kozlowska's work, Schacht, et al. [62] adjusted the two parameters of the bPCP-SAFT equation, association volume, $\kappa^{A i B j}$, and energy interaction parameter, $\varepsilon / k_{B}$, and applied the linear temperature-dependent binary interaction parameters based on the experiment data of hyperbranched polyglycerol + methanol $+\mathrm{CO}_{2}$ with a specific composition. The obtained parameters were then used to predict the same system with different compositions and different polymer molecular weight. The bPCP-SAFT model with the optimized parameters predicted the ternary system with various compositions very well. It also showed a reasonable prediction for the same system where the polymer molecular weight was different, although the dew points were not described very accurately at higher molecular weight. However, the authors concluded that structural effects of the hyperbranched polyglycerol were not properly captured by the bPCP-SAFT model due to its incapability of taking into account intramolecular interactions. It was also verified by the fact that the prediction of the ternary system with bPCP-SAFT model requires a temperature-dependent binary parameter while the PC-SAFT EOS usually just needs a temperature-independent binary parameter when giving a reasonable prediction of the liquid-liquid-vapor equilibrium [62].

\section{FUTURE WORK}

In spite of a number of progresses on the highpressure phase behavior work in the past eight years, most studies still focus on the commercially available hyperbranched polymers, such as hyperbranched polyglycerol from HyperPolymers $\mathrm{GmbH}$, Boltorn ${ }^{\circledR}$ series hyperbranched polyester supplied by Perstorp $A B$, and Hybrane ${ }^{\circledR}$ series hyperbranched polyesteramide from DSM. On one hand, these commercial hyperbranched polymers are beneficial for the phase behavior researchers, who do not have to worry about the synthesis, purification, and characterization process. The control of detailed polymer structure and polydispersity and the removal of side products, catalysts, and remained reactants have been always a challenge for polymer chemists, let alone phase behavior researchers. Using commercial products, they are able to focus on their familiar phase behavior determination and modeling and be more productive and efficient. On the other hand, however, commercial products are synthesized based on a standard process with a specific range of degrees of branching, numbers and types of functional groups, and molecular weights, limiting the complete understanding of the above effects on the phase behavior, which is almost impossible for researchers to investigate the influence of a single factor while fixing the other factors unchanged with commercial hyperbranched polymers. In other words, commercial products do not allow the researchers to customize the structure of hyperbranched polymers for isolation of each polymer architectural effect alone. From this point of view, Gregorowicz et al. [32] and Tryznowski, et al. [33] made a great leap in customizing the polymer architecture, although they mainly focused on the effects of terminal groups on the phase behavior of hyperbranched polymers in supercritical $\mathrm{CO}_{2}$ and their attempts on the discussion of internal structure's effect cannot eliminate molecular weight effect. It is still in infancy when talking about customizing desired structures of hyperbranched polymers for the investigation of each factor's influence on the phase behavior, which is a goal for future experimental work.

Another goal is to compare the phase behavior of a hyperbranched polymer with its comparative linear polymer in a supercritical fluid. It has been known for years that relative to linear polymers, hyperbranched polymers posses a number of unique properties, for example, much lower viscosity and higher thermal stability. However, the difference in phase behavior of hyperbranched polymers and its linear analogue is still not very clear. Schacht, et al. [62, 63] made a comparison of the phase behavior of hyperbranched polyglycerol + methanol $+\mathrm{CO}_{2}$ and the ternary system of linear polyglycerol in the same solvents. Although they found some interesting observations on the difference in molecular weight dependence, the phase behavior data of hyperbranched polymer and linear polymer system cannot be directly compared on the same condition because molecular weight effect cannot be eliminated. Further, the phase transition points of hyperbranched and linear polymers almost fall on top of each other probably due to the existence of strong solvent methanol. Tryznowski, et al. [33] also tried comparing their synthesized hyperbranched polycarbonate with linear polymer, but did not make any conclusion also due to the difficulties in elimination 
of molecular weight or, in another word, chain length effects.

Therefore, to the perspective of comparing a hyperbranched polymer with its corresponding linear polymer, one of the challenges comes from the difficulties in synthesis of the hyperbranched polymer and its linear analogue at the same molecular weight level to eliminate molecular weight effect on the phase behavior, which again traces back to the goal of customizing hyperbranched polymers mentioned above. Further, the selection of a solvent is also important for the comparison. A solvent with a strong solvent power may mask the phase behavior difference between a hyperbranched polymer and its comparative linear analogue, since both the hyperbranched and linear polymers can form a single phase easily at room conditions in such a strong solvent. That is one of the reasons for the high-pressure study with a supercritical fluid such as $\mathrm{CO}_{2}$, ethane, or propane that exhibits weak solvent power. A slight structural difference can spread out and be clearly reflected on the phase diagram of a polymer system. Wu, et al. [88, 89] made a preliminary study on the comparison of phase behavior of a synthesized star polymer with its corresponding linear polymer in supercritical propane. Apparently, however, more studies need to be done for a complete comparison of the phase behavior of hyperbranched polymers and its linear analogue in $s$ supercritical fluid.

In terms of thermodynamic modeling, it is still a challenge for the prediction of the architectural effect on the hyperbranched polymer system phase behavior at elevated pressures. Although Kozlowska, et al. [60] tried the SAFT-based EOS to predict the high-pressure phase behavior by adding a branching term to the original PCP-SAFT equation, it still seems impossible to capture the structural effect with the same parameters in the SAFT-based equation [62] and this model also has to assume that the branched structure is only composed of branching tetramers instead of any other possible arbitrary structures that actually exist in a hyperbranched polymer [60]. Other models, as far as is concerned, only focus on the prediction of phase behavior of hyperbranched polymer systems at low pressures, most of which, for example, UNIFAC-FV, only deal with incompressible models and hence cannot extent to high-pressure conditions, where the dependence of thermodynamic properties on the pressure has to be considered. Up to now, LCT model seems a promising method for the prediction for the hyperbranched polymers at high pressures. Unlike SAFT-based equation in which none of the parameters was originally set to account for the structural effect and UNIFAC-FV that can only deal with incompressible systems, LCT model performs the calculation of the statistical partition function that directly depends on the polymer structure for both incompressible and compressible systems [90]. Along with their previous studies on the incompressible LCT model [41-44, 74, 75], Enders' group started working on the modeling of the thermodynamic properties of pure $n$-alkanes at high pressures with compressible LCT model, namely LCT equation of state (LCT-EOS), recently [90]. Although a lot of work needs to be done, LCT-EOS gives a direction for the future modeling work that can take into account both the structural effect and the pressure dependence.

Another challenge for the future work is the modeling of hyperbranched copolymer or the hyperbranched polymer with different types of terminal groups. Up to now, all the models only focus on the hyperbranched homopolymer, especially those commercially available hyperbranched polymers that are only composed of one type of segment. There is a gap for the extension to the prediction of the phase behavior of hyperbranched polymers composed of several different types of segments, such as hyperbranched polymers with a different type of terminal group proposed by Gregorowicz, et al. [32] and the star polymers with a divinylbenzene core and methacrylate copolymer arms from $\mathrm{Wu}$, et al. [88, 89]. Further modeling work should be considered on those polymers.

\section{REFERENCES}

[1] McHugh MA, Krukonis VJ. Supercritical fluid extraction: principles and practice. Boston: Butterworth-Heinemann 1994.

[2] Kirby CF, McHugh MA. Phase behavior of polymers in supercritical fluid solvents. Chem Rev 1999; 99: 565-602. http://dx.doi.org/10.1021/cr970046j

[3] Gao C, Yan D. Hyperbranched polymers: from synthesis to applications. Prog Polym Sci 2004; 29: 183-275. http://dx.doi.org/10.1016/j.progpolymsci.2003.12.002

[4] Ranganathan K, Deng R, Kainthan RK, Wu C, Brooks DE, Kizhakkedathu JN. Synthesis of thermoresponsive mixed arm star polymers by combination of RAFT and ATRP from a multifunctional core and its self-assembly in water. Macromolecules 2008; 41: 4226-34. http://dx.doi.org/10.1021/ma800094d

[5] Sunder A, Hanselmann R, Frey H, Mulhaupt R. Controlled synthesis of hyperbranched polyglycerols by ring-opening multibranching polymerization. Macromolecules 1999; 32: 4240-6.

http://dx.doi.org/10.1021/ma990090w 
[6] Kim YH. Hyperbranched polymers 10 years after. J Polym Sci A Polym Chem 1998; 36: 1685-98.

http://dx.doi.org/10.1002/(SICl)10990518(199808)36:11<1685::AID-POLA1>3.0.CO:2-B

[7] Seiler M. Hyperbranched polymers: Phase behavior and new applications in the field of chemical engineering. Fluid Phase Equilib 2006; 241: 155-74.

http://dx.doi.org/10.1016/j.fluid.2005.12.042

[8] Frechet J, Tomalia D. Dendrimers and other dendritic polymers. West Sussex, UK: John Wiley \& Sons Ltd. 2001. http://dx.doi.org/10.1002/0470845821

[9] Seiler M. Dendritic polymers - Interdisciplinary research and emerging applications from unique structural properties. Chem Eng Technol 2002; 25: 237-53.

http://dx.doi.org/10.1002/1521-4125(200203)25:3<237::AIDCEAT237>3.0.CO;2-4

[10] Jikei M, Kakimoto M. Hyperbranched polymers: a promising new class of materials. Prog Polym Sci 2001; 26: 1233-85. http://dx.doi.org/10.1016/S0079-6700(01)00018-1

[11] Yates CR, Hayes W. Synthesis and applications of hyperbranched polymers. Eur Polym J 2004; 40: 1257-81. http://dx.doi.org/10.1016/j.eurpolymj.2004.02.007

[12] Ye ZB, Zhu SP. Newtonian flow behavior of hyperbranched high-molecular-weight polyethylenes produced with a $\mathrm{Pd}$ diimine catalyst and its dependence on chain topology. Macromolecules 2003; 36: 2194-7. http://dx.doi.org/10.1021/ma0340053

[13] Ye ZB, AlObaidi F, Zhu SP. Melt rheological properties of branched polyethylenes produced with $\mathrm{Pd}$ - and Ni-diimine catalysts. Macromol Chem Phys 2004; 205: 897-906. http://dx.doi.org/10.1002/macp.200300128

[14] Guan ZB, Cotts PM, McCord EF, McLain SJ. Chain walking: a new strategy to control polymer topology. Science 1999; 283: 2059-62.

http://dx.doi.org/10.1126/science.283.5410.2059

[15] Seiler M, Arlt W, Kautz H, Frey H. Experimental data and theoretical considerations on vapor-liquid and liquid-liquid equilibria of hyperbranched polyglycerol and PVA solutions. Fluid Phase Equilib 2002; 201: 359-79.

http://dx.doi.org/10.1016/S0378-3812(02)00082-1

[16] Seiler M, Kohler D, Arlt W. Hyperbranched polymers: new selective solvents for extractive distillation and solvent extraction. Sep Purif Technol 2002; 29: 245-63. http://dx.doi.org/10.1016/S1383-5866(02)00163-6

[17] Seiler M, Buggert M, Kavarnou A, Arlt W. From alcohols to hyperbranched polymers: The influence of differently branched additives on the vapor-liquid equilibria of selected azeotropic systems. J Chem Eng Data 2003; 48: 933-7. http://dx.doi.org/10.1021/je025644w

[18] Seiler M, Jork C, Kavarnou A, Arlt W, Hirsch R. Separation of azeotropic mixtures using hyperbranched polymers or ionic liquids. AIChE J 2004; 50: 2439-54. http://dx.doi.org/10.1002/aic.10249

[19] Rolker J, Seiler M, Mokrushina L, Arlt W. Potential of branched polymers in the field of gas absorption: Experimental gas Solubilities and Modeling. Ind Eng Chem Res 2007; 46: 6572-83. http://dx.doi.org/10.1021/ie061637f

[20] Wang JL, Ye ZB, Zhu SP. Topology-engineered hyperbranched high-molecular-weight polyethylenes as lubricant viscosity-index improvers of high shear stability. Ind Eng Chem Res 2007; 46: 1174-8. http://dx.doi.org/10.1021/ie0613624

[21] Chen Y, Shen Z, Frey H, Perez-Prieto J, Stiriba SE. Synergistic assembly of hyperbranched polyethylenimine and fatty acids leading to unusual supramolecular nanocapsules. Chem Commun 2005: 755-7.

http://dx.doi.org/10.1039/b414046j
[22]

Kim TH, Cook SE, Arote RB, Cho MH, Nah JW, Choi YJ, et al. A degradable hyperbranched poly(ester amine) based on poloxamer diacrylate and polyethylenimine as a gene carrier. Macromol Biosci 2007; 7: 611-9.

http://dx.doi.org/10.1002/mabi.200600245

[23] Wan DC, Yuan JJ, Pu HT. Macromolecular nanocapsule derived from hyperbranched polyethylenimine (HPEI): mechanism of guest encapsulation versus molecular parameters. Macromolecules 2009; 42: 1533-40. http://dx.doi.org/10.1021/ma8026707

[24] Suttiruengwong S, Rolker J, Smirnova I, Arlt W, Seiler M, Luderitz L, et al. Hyperbranched polymers as drug carriers: Microencapsulation and release kinetics. Pharm Dev Technol 2006; 11: 55-70.

http://dx.doi.org/10.1080/10837450500463919

[25] Jang WD, Selim KMK, Lee CH, Kang IK. Bioinspired application of dendrimers: From bio-mimicry to biomedical applications. Prog Polym Sci 2009; 34: 1-23.

http://dx.doi.org/10.1016/j.progpolymsci.2008.08.003

[26] Irfan M, Seiler M. Encapsulation using hyperbranched polymers: from research and technologies to emerging applications. Ind Eng Chem Res 2010; 49: 1169-96. http://dx.doi.org/10.1021/ie900216r

[27] Reverchon E. Supercritical antisolvent precipitation of microand nano-particles. J Supercrit Fluids 1999; 15: 1-21. http://dx.doi.org/10.1016/S0896-8446(98)00129-6

[28] Cooper Al. Polymer synthesis and processing using supercritical carbon dioxide. J Mater Chem 2000; 10: 207-34. http://dx.doi.org/10.1039/a906486i

[29] Tomasko DL, Li HB, Liu DH, Han XM, Wingert MJ, Lee LJ, et al. A review of $\mathrm{CO}(2)$ applications in the processing of polymers. Ind Eng Chem Res 2003; 42: 6431-56. http://dx.doi.org/10.1021/ie030199z

[30] Yeo SD, Kiran E. Formation of polymer particles with supercritical fluids: A review. J Supercrit Fluids 2005; 34: 287-308.

http://dx.doi.org/10.1016/j.supflu.2004.10.006

[31] Perstorp [homepage on the Internet]. Sweden: Perstorp Inc.; c2012 [cited 2012 Nov 22]: Available from: www.perstorp.com/upload/boltorn_0910.pdf

[32] Gregorowicz J, Fras Z, Parzuchowski P, Rokicki G, Kusznerczuk M, Dziewulski $S$. Phase behaviour of hyperbranched polyesters and polyethers with modified terminal $\mathrm{OH}$ groups in supercritical solvents. J Supercrit Fluids 2010; 55: 786-96. http://dx.doi.org/10.1016/j.supflu.2010.09.005

[33] Tryznowski M, Tomczyk K, Fras Z, Gregorowicz J, Rokicki G, Wawrzynska E, et al. Aliphatic hyperbranched polycarbonates: synthesis, characterization, and solubility in supercritical carbon dioxide. Macromolecules 2012; 45: 6819-29. http://dx.doi.org/10.1021/ma3011153

[34] Domanska U, Zolek-Tryznowska Z. Temperature and composition dependence of the density and viscosity of binary mixtures of (hyperbranched polymer, B-U3000+1alcohol, or ether). J Chem Thermodyn 2009; 41: 821-8. http://dx.doi.org/10.1016/j.jct.2009.02.003

[35] Domanska U, Zolek-Tryznowska Z, Pobudkowska A. Separation of hexane/ethanol Mixtures. LLE of ternary systems (ionic liquid or hyperbranched polymer plus ethanol plus hexane) at $\mathrm{T}=298.15 \mathrm{~K}$. J Chem Eng Data 2009; 54: 972-6. http://dx.doi.org/10.1021/je8007588

[36] Domanska U, Paduszynski K, Zolek-Tryznowska Z. Liquidliquid phase equilibria of binary systems containing hyperbranched polymer B-U3000: experimental study and modeling in terms of lattice cluster theory. J Chem Eng Data 2010; 55: 3842-6.

http://dx.doi.org/10.1021/je100334n 
[37] Domanska U, Zolek-Tryznowska Z. Measurements of the density and viscosity of binary mixtures of (hyper-branched polymer, B-H2004+1-butanol, or 1-hexanol, or 1-octanol, or methyl tert-butyl ether). J Chem Thermodyn 2010; 42: 651-8. http://dx.doi.org/10.1016/j.jct.2009.12.005

[38] Domanska U, Paduszynski K, Zolek-Tryznowska Z. (Liquid plus liquid) equilibria of binary systems containing hyperbranched polymer Boltorn H2004-Experimental study and modelling in terms of lattice-cluster theory. J Chem Thermodyn 2011; 43: 167-71. http://dx.doi.org/10.1016/j.jct.2010.08.013

[39] Domanska U, Zolek-Tryznowska Z. Solubility of hyperbranched polymer, Boltorn W-3000, in alcohols, ethers and hydrocarbons. J Chem Thermodyn 2010; 42: 1304-9. http://dx.doi.org/10.1016/j.jct.2010.05.013

[40] Domanska U, Zołek-Tryznowska Z, Tshibangu MM, Ramjugernath D, Letcher TM. Separation of an alcohol and a tetrahydrofuran, methyl tert-butyl ether, or ethyl tert-butyl ether by solvent extraction with a hyperbranched polymer at $\mathrm{T}=298.15 \mathrm{~K}$. J Chem Eng Data 2010; 55: 2879-85. http://dx.doi.org/10.1021/je901038q

[41] Zeiner T, Enders S. Phase behavior of hyperbranched polymer solutions in mixed solvents. Chem Eng Sci 2011; 66: 5244-52.

http://dx.doi.org/10.1016/j.ces.2011.07.016

[42] Zeiner T, Schrader P, Enders S, Browarzik D. Phase- and interfacial behavior of hyperbranched polymer solutions. Fluid Phase Equilib 2011; 302: 321-30. http://dx.doi.org/10.1016/j.fluid.2010.07.021

[43] Browarzik C, Browarzik D, Enders S. Liquid-liquid phase equilibria of hyperbranched polymers-Experimental study and modeling. Fluid Phase Equilib 2012; 328: 49-60. http://dx.doi.org/10.1016/j.fluid.2012.05.018

[44] Schrader P, Zeiner T, Browarzik C, Puyan MJ, Enders S. Phase behaviour of hyperbranched polymers in demixed solvents. Mol Phys 2012; 110: 1359-73. http://dx.doi.org/10.1080/00268976.2011.648964

[45] Jang JG, Bae YC. Phase behaviors of hyperbranched polymer solutions. Polymer 1999; 40: 6761-8. http://dx.doi.org/10.1016/S0032-3861(99)00005-1

[46] Seiler M, Jork C, Arlt W. Phasenverhalten von hochselektiven nichtflüchtigen Flüssigkeiten mit designbarem Eigenschaftsprofil und neue Anwendungen in der thermischen Verfahrenstechnik. Chem Ing Tech 2004; 76: 735-44. http://dx.doi.org/10.1002/cite.200400064

[47] Seiler M, Rolker J, Mokrushina L, Kautz H, Frey H, Arlt W. Vapor-liquid equilibria in dendrimer and hyperbranched polymer solutions: experimental data and modeling using UNIFAC-FV. Fluid Phase Equilib 2004; 221: 83-96. http://dx.doi.org/10.1016/j.fluid.2004.04.002

[48] Sadowski G, Mokrushina LV, Arlt W. Finite and infinite dilution activity coefficients in polycarbonate systems. Fluid Phase Equilib 1997; 139: 391-403.

http://dx.doi.org/10.1016/S0378-3812(97)00142-8

[49] Dohrn R, Brunner G. High-pressure fluid-phase equilibria: Experimental methods and systems investigated (19881993). Fluid Phase Equilib 1995; 106: 213-82. http://dx.doi.org/10.1016/0378-3812(95)02703-H

[50] Christov M, Dohrn R. High-pressure fluid phase equilibria Experimental methods and systems investigated (19941999). Fluid Phase Equilib 2002; 202: 153-218. http://dx.doi.org/10.1016/S0378-3812(02)00096-1

[51] Dohrn R, Peper S, Fonseca JMS. High-pressure fluid-phase equilibria: Experimental methods and systems investigated (2000-2004). Fluid Phase Equilib 2010; 288: 1-54. http://dx.doi.org/10.1016/j.fluid.2009.08.008
[52] Fonseca JMS, Dohrn R, Peper S. High-pressure fluid-phase equilibria: Experimental methods and systems investigated (2005-2008). Fluid Phase Equilib 2011; 300: 1-69. http://dx.doi.org/10.1016/i.fluid.2010.09.017

[53] Dohrn R, Fonseca JMS, Peper S. Experimental methods for phase equilibria at high pressures. In: Prausnitz JM, editors. Annual Review of Chemical and Biomolecular Engineering, Vol 3. Palo Alto: Annual Reviews 2012; p. 343-67.

[54] De Loos TW, Van der Kooi HJ, Ott PL. Vapor-liquid critical curve of the system ethane + 2-methylpropane. J Chem Eng Data 1986; 31: 166-8.

http://dx.doi.org/10.1021/je00044a011

[55] Shariati A, Peters CJ. Measurements and modeling of the phase behavior of ternary systems of interest for the GAS process: I. The system carbon dioxide+1-propanol+salicylic acid. J Supercrit Fluids 2002; 23: 195-208.

http://dx.doi.org/10.1016/S0896-8446(02)00006-2

[56] Wu Y, Bamgbade B, Liu K, McHugh MA, Baled H, Enick RM, et al. Experimental measurements and equation of state modeling of liquid densities for long-chain n-alkanes at pressures to $265 \mathrm{MPa}$ and temperatures to $523 \mathrm{~K}$. Fluid Phase Equilib 2011; 311: 17-24. http://dx.doi.org/10.1016/j.fluid.2011.08.020

[57] Seiler M, Rolker J, Arlt W. Phase behavior and thermodynamic phenomena of hyperbranched polymer solutions. Macromolecules 2003; 36: 2085-92. http://dx.doi.org/10.1021/ma025994n

[58] Bungert B, Tippl R, Sadowski G, Arlt W. Separation of nonvolatile components by expansion with high-pressure gases. In: vonRohr PR, Trepp C, editors. High Pressure Chemical Engineering. Amsterdam: Elsevier Science Publ B V 1996; $p$. 519-24. http://dx.doi.org/10.1016/S0378-3812(97)00167-2

[59] Bungert B, Sadowski G, Arlt W. Supercritical antisolvent fractionation: measurements in the systems monodisperse and bidisperse polystyrene cyclohexane carbon dioxide. Fluid Phase Equilib 1997; 139: 349-59.

[60] Kozlowska MK, Jurgens BF, Schacht CS, Gross J, de Loos TW. Phase behavior of hyperbranched polymer systems: experiments and application of the perturbed-chain polar SAFT equation of state. J Phys Chem B 2009; 113: 1022-9. http://dx.doi.org/10.1021/jp804459x

[61] Portela VM, Straver EJM, de Loos TW. High-pressure phase behavior of the system propane-Boltorn H3200. J Chem Eng Data 2009; 54: 2593-8. http://dx.doi.org/10.1021/je900130y

[62] Schacht CS, Bahrarnali S, Wilms D, Frey H, Gross J, de Loos TW. Phase behavior of the system hyperbranched polyglycerol plus methanol plus carbon dioxide. Fluid Phase Equilib 2010; 299: 252-8. http://dx.doi.org/10.1016/j.fluid.2010.09.028

[63] Schacht CS, Schuell C, Frey H, de Loos TW, Gross J. Phase Behavior of the System Linear Polyglycerol plus Methanol plus Carbon Dioxide. J Chem Eng Data 2011; 56: 2927-31. http://dx.doi.org/10.1021/je200156e

[64] Lue L. Volumetric behavior of athermal dendritic polymers: Monte Carlo simulation. Macromolecules 2000; 33: 2266-72. http://dx.doi.org/10.1021/ma991340b

[65] Timoshenko EG, Kuznetsov YA. Equilibrium and kinetics at the coil-to-globule transition of star and comb heteropolymers in infinitely dilute solutions. Colloid Surf A-Physicochem Eng Asp 2001; 190: 135-44. http://dx.doi.org/10.1016/S0927-7757(01)00673-2

[66] Steinhauser MO. A molecular dynamics study of the influence of chain branching on the properties of polymer systems. PhD Dissertation, Johannes Gutenberg-Universitat Mainz, 2001. 
[67] Jang JG, Noh ST, Bae YC. Liquid-liquid equilibria of dendrimer in polar solvent. J Phys Chem A 2000; 104: 74047. http://dx.doi.org/10.1021/jp994376e

[68] Jang JG, Bae YC. Vapor-liquid equilibria of dendrimer solutions: the effect of endgroups at the periphery of dendrimer molecules. Chem Phys 2001; 269: 285-94. http://dx.doi.org/10.1016/S0301-0104(01)00259-2

[69] Jang JG, Bae YC. Phase behavior of hyperbranched polymer solutions with specific interactions. J Chem Phys 2001; 114: 5034-42.

http://dx.doi.org/10.1063/1.1329647

[70] Jang JG, Bae YC. Phase behaviors of dendrimer/solvent systems: Molecular thermodynamics approach. J Chem Phys 2002; 116: 3484-92. http://dx.doi.org/10.1063/1.1436474

[71] Jang JG, Huh JY, Bae YC. Phase behavior of dendritic polymer/polar solvent: the effects of compressibility, architecture and hydrogen bondings. Fluid Phase Equilib 2002; 194: 675-88. http://dx.doi.org/10.1016/S0378-3812(01)00683-5

[72] Kouskoumvekaki IA, Giesen R, Michelsen ML, Kontogeorgis GM. Free-volume activity coefficient models for dendrimer solutions. Ind Eng Chem Res 2002; 41: 4848-53. http://dx.doi.org/10.1021/ie020034a

[73] Rissanou AN, Economou IG, Panagiotopoulos AZ. Monte Carlo simulation of the phase behavior of model dendrimers. Macromolecules 2006; 39: 6298-305. http://dx.doi.org/10.1021/ma061339u

[74] Zeiner T, Browarzik D, Enders S. Calculation of the liquidliquid equilibrium of aqueous solutions of hyperbranched polymers. Fluid Phase Equilib 2009; 286: 127-33. http://dx.doi.org/10.1016/j.fluid.2009.08.013

[75] Zeiner T, Browarzik C, Browarzik D, Enders S. Calculation of the (liquid + liquid) equilibrium of solutions of hyperbranched polymers with the lattice-cluster theory combined with an association model. J Chem Thermodyn 2011; 43: 1969-76. http://dx.doi.org/10.1016/j.jct.2011.07.010

[76] Wertheim MS. Fluids with highly directional attractive forces. 1. Statistical thermodynamics. J Stat Phys 1984; 35: 19-34. http://dx.doi.org/10.1007/BF01017362

[77] Wertheim MS. Fluids with highly directional attractive forces. 2. Thermodynamic perturbation - theory and integral equations. J Stat Phys 1984; 35: 35-47. http://dx.doi.org/10.1007/BF01017363

[78] Wertheim MS. Fluids with highly directional attractive forces. 3. Multiple attraction sites. J Stat Phys 1986; 42: 459-76. http://dx.doi.org/10.1007/BF01127721

[79] Wertheim MS. Fluids with highly directional attractive forces. 4. Equilibrium polymerization. J Stat Phys 1986; 42: 477-92. http://dx.doi.org/10.1007/BF01127722
[80] Simha R, Utracki LA. PVT Properties of Linear and Dendritic Polymers. J Polym Sci B Polym Phys 2010; 48: 322-32. http://dx.doi.org/10.1002/polb.21893

[81] Hay G, Mackay ME, Hawker CJ. Thermodynamic properties of dendrimers compared with linear polymers: General observations. J Polym Sci B Polym Phys 2001; 39: 1766-77. http://dx.doi.org/10.1002/polb.1150

[82] Gross J, Sadowski G. Perturbed-chain SAFT: An equation of state based on a perturbation theory for chain molecules. Ind Eng Chem Res 2001; 40: 1244-60. http://dx.doi.org/10.1021/ie0003887

[83] Gross J, Sadowski G. Application of the perturbed-chain SAFT equation of state to associating systems. Ind Eng Chem Res 2002; 41: 5510-5. http://dx.doi.org/10.1021/ie010954d

[84] Gross J, Vrabec J. An equation-of-state contribution for polar components: Dipolar molecules. AIChE J 2006; 52: 1194204. http://dx.doi.org/10.1002/aic.10683

[85] Kleiner M, Gross J. An equation of state contribution for polar components: polarizable dipoles. AIChE J 2006; 52: 195161.

http://dx.doi.org/10.1002/aic.10791

[86] Vrabec J, Gross J. Vapor-liquid equilibria simulation and an equation of state contribution for dipole-quadrupole interactions. J Phys Chem B 2008; 112: 51-60. http://dx.doi.org/10.1021/jp072619u

[87] Blas FJ, Vega LF. Thermodynamic properties and phase equilibria of branched chain fluids using first- and secondorder Wertheim's thermodynamic perturbation theory. J Chem Phys 2001; 115: 3906-15. http://dx.doi.org/10.1063/1.1388544

[88] Wu Y, Newkirk MS, Babatunde B, McHugh MA, Krukonis VJ, Wetmore P. Polymer architectural effects on solution behavior of high pressures: linear, hyperbranched, and star polymers in SCF and liquid solvents. 10th International Symposium on Supercritical Fluids (ISSF); 2012: San Francisco, CA, USA.

[89] Wu Y, Newkirk MS, McHugh MA. Solution behavior at high pressures: linear to star polymers in SCF and liquid solvents. 2012 American Institute of Chemical Engineers (AIChE) Annual Meeting; 2012: Pittsburgh, PA, USA.

[90] Langenbach K, Enders S. Development of an EOS based on lattice cluster theory for pure components. Fluid Phase Equilib 2012; 331: 58-79. http://dx.doi.org/10.1016/j.fluid.2012.06.022

Received on 26-11-2012

Accepted on 16-02-2013

Published on 28-02-2013

DOI: http://dx.doi.org/10.6000/1929-5030.2013.02.01.5

(C) 2012 Yue Wu; Licensee Lifescience Global.

This is an open access article licensed under the terms of the Creative Commons Attribution Non-Commercial License (http://creativecommons.org/licenses/by-nc/3.0/) which permits unrestricted, non-commercial use, distribution and reproduction in any medium, provided the work is properly cited. 